\title{
CD8 Knockout Mice Are Protected from Challenge by Vaccination with WR201, a Live Attenuated Mutant of Brucella melitensis
}

\author{
Samuel L. Yingst, ${ }^{1,2}$ Mina Izadjoo, ${ }^{3}$ and David L. Hoover ${ }^{4}$ \\ ${ }^{1}$ Department of Bacterial Diseases, Walter Reed Army Institute of Research, Silver Spring, MD 20910-5100, USA \\ ${ }^{2}$ Armed Forces Research Institute of Medical Sciences, 315/6 Rajvithi, Bangkok 10400, Thailand \\ ${ }^{3}$ Diagnostics and Translational Research Center, Henry M. Jackson Foundation for the Advancement of Military Medicine, \\ 401 Professional Drive, Suite 210, Gaithersburg, MD 20879, USA \\ ${ }^{4}$ DHMD Consulting, LLC, 13725 Drake Drive, Rockville, MD 20853, USA
}

Correspondence should be addressed to Samuel L. Yingst; samuel.yingst@afrims.org

Received 17 June 2013; Accepted 9 September 2013

Academic Editor: Stephane Becart

Copyright (C) 2013 Samuel L. Yingst et al. This is an open access article distributed under the Creative Commons Attribution License, which permits unrestricted use, distribution, and reproduction in any medium, provided the original work is properly cited.

\begin{abstract}
CD8+ T cells have been reported to play an important role in defense against $B$. abortus infection in mouse models. In the present report, we use CD8 knockout mice to further elucidate the role of these cells in protection from $B$. melitensis infection. Mice were immunized orally by administration of B. melitensis WR201, a purine auxotrophic attenuated vaccine strain, then challenged intranasally with B. melitensis 16M. In some experiments, persistence of WR201 in the spleens of CD8 knockout mice was slightly longer than that in the spleens of normal mice. However, development of anti-LPS serum antibody, antigen-induced production of $\gamma$-interferon (IFN- $\gamma$ ) by immune splenic lymphocytes, protection against intranasal challenge, and recovery of nonimmunized animals from intranasal challenge were similar between normal and knockout animals. Further, primary Brucella infection was not exacerbated in perforin knockout and Fas-deficient mice and these animals' anti-Brucella immune responses were indistinguishable from those of normal mice. These results indicate that CD8+ T cells do not play an essential role as either cytotoxic cells or IFN$\gamma$ producers, yet they do participate in a specific immune response to immunization and challenge in this murine model of $B$. melitensis infection.
\end{abstract}

\section{Introduction}

Brucellosis causes loss of livestock productivity and threatens human health worldwide [1]. The threat is most pronounced in developing nations, but even Europe and North America remain at significant risk $[2,3]$. The predominant Brucella species in both animal and human infections is Brucella melitensis [4]. A vaccine for B. melitensis for use in humans would be a boon to millions of agriculture workers worldwide [5] and may be an important goal for protection against bioterrorism [6].

To date, the most successful brucellosis vaccine preparations (used in livestock species) have been modified live derivatives of virulent Brucella [7, 8]. However, some of these vaccines are pathogenic in humans [9]. Additionally, modified live vaccines may induce abortion to livestock if administered during pregnancy or to other animals in contact with pregnant animals [10,11]. Despite being perhaps less efficacious, subunit vaccines may have safety advantages over live attenuated candidates. Delineation of the immune mechanisms responsible for vaccine-induced protection may focus subunit vaccine development by suggesting potential immune correlates and adjuvants tailored to evoke a desired response.

Immunization with $B$. melitensis WR201, an attenuated purine auxotroph, protects mice against intranasal challenge with virulent $B$. melitensis $16 \mathrm{M}$ [12]. Protection is associated with production of anti-lipopolysaccharide (LPS) antibodies 
and production of IFN- $\gamma$ by antigen-stimulated immune spleen cells. The contribution of CD8 $+\mathrm{T}$ cells in protection has not been examined in this model.

Antibody to the O-polysaccharide of Brucella LPS has been firmly established as an important mediator of antiBrucella effects in murine models of secondary immunity [13, 14]. However, cellular immunity also plays a key role $[15,16]$. The production of IFN- $\gamma$ is essential for protection, clearance, and survival in the face of virulent Brucella challenge in the mouse model [17]. IFN- $\gamma$ is produced in vivo predominantly by CD4+ T cells and to a lesser extent by CD8+ T cells $[16,18,19]$. Both CD8+ and CD4+ T cells respond specifically to $B$. abortus in mice, CD8+ T cells may function as specific cytotoxic cells in brucellosis caused by B. abortus $[16,20$, 21 ], and one study indicated that immune modulation could result in an effective CD8+ T-cell role in secondary immunity [22]. On the other hand, other studies seem to indicate that the role of CD8+ T cells is relatively minor in the immune response to $B$. abortus $[17,23]$. One virulence mechanism of both $B$. abortus [24] and B. melitensis [25] may be evasion of CD8+ T cell adaptive immunity, and $B$. melitensis epitopes of CD8+ T cell IFN- $\gamma$ production and cytotoxicity have been identified [26]. In contrast, CD8+ T cells appear to be dispensable in a model of primary B. melitensis infection [27]. The study reported here further elucidates the role of CD8+ $\mathrm{T}$ cells in brucellosis by evaluating the requirement for the cell type in secondary immunity resulting from modified live organism immunization in a mouse model of $B$. melitensis.

We found that CD8+ $\mathrm{T}$ cells from immunized mice specifically produce significant amounts of IFN- $\gamma$ in vitro. However, we also found that these cells are not essential for clearance of attenuated or virulent $B$. melitensis nor for WR201-induced protection against intranasal challenge. Moreover, the key CD8+ T cell mediators of cytotoxicity (perforin and Fas) appear to play no role in elimination of $B$. melitensis in these studies. These data indicate a more limited role for CD8+ T cells in secondary immunity to B. melitensis than what has been suggested from previously published work using B. abortus.

\section{Materials and Methods}

2.1. Bacteria and Bacterial Products. B. melitensis $16 \mathrm{M}$ and WR201 from our culture collection were prepared as described previously [12]. WR201 from stocks frozen in 50\% glycerol was incubated overnight in Brucella broth in a shaker flask at $37^{\circ} \mathrm{C}$. One $\mathrm{mL}$ aliquots of this culture were then plated on Brucella agar and incubated at $37^{\circ} \mathrm{C}$ for an additional three days. The bacterial "lawn" was then scraped from the agar surface, resuspended in $0.9 \%$ sodium chloride solution (saline), pelleted, washed twice with saline, and adjusted based on optical density to $5 \times 10^{11}$ colony forming units $(\mathrm{CFU}) / \mathrm{mL}$ in saline. In our experience this is the safest and most convenient method by which to obtain brucellae at these high concentrations. On the other hand, B. melitensis $16 \mathrm{M}$ from stocks frozen in $50 \%$ glycerol was incubated overnight in Brucella broth in a shaker flask at $37^{\circ} \mathrm{C}$, pelleted, washed with saline, and diluted to $3.3 \times 10^{5} \mathrm{CFU} / \mathrm{mL}-$ a concentration easy to obtain directly from broth. CFU concentration was verified by serial dilution and plating on Brucella agar. Rough Brucella lysate (RFBL) and Brucella LPS were prepared as previously described [12].

2.2. Immunization and Challenge of Mice. Six-week-old C57BL/6, B6.129S2-cd8a ${ }^{\text {tm1Mak }}$ (CD8 knockout), C57BL/6Pfp $^{\text {tm1Sdz }}$ (perforin knockout), and B6.MRL-Fas ${ }^{\text {lpr }}$ (Fas receptor deficient mutant) mice were obtained from Jackson Laboratories (Bar Harbor, ME, USA). One pair of experiments, which used males, was conducted to evaluate kinetics of immunization and challenge in CD8 knockout compared to normal C57BL/6 mice. A subsequent pair of experiments, using females, compared the kinetics of clearance of WR201 from CD8 and perforin knockout, Fas mutant, and normal C57BL/ 6 mice. Animals were housed in animal biosafety level 3 facilities. Immunization and challenge procedures were performed as previously described [28]. Briefly, mice were acclimated for one week, then gavaged with $200 \mu \mathrm{L} 2.5 \%$ sodium bicarbonate followed by $10^{11}$ CFU WR201 also in $200 \mu \mathrm{L}$. Sham-immunized mice received an equal volume $(200 \mu \mathrm{L})$ of sodium bicarbonate and saline. Seven or eight weeks following immunization, mice were either euthanized to obtain tissues for in vitro assays or challenged. For challenge, mice were anesthetized with $0.3 \mathrm{mg}$ xylazine and $1 \mathrm{mg}$ ketamine. $1 \times 10^{4} \mathrm{CFU} 16 \mathrm{M}$ in $30 \mu \mathrm{L}$ were then administered dropwise into the external nares with a micropipette.

\subsection{Determination of Bacterial Infection and Immune Re-} sponses. Blood was obtained by cardiac puncture from mice euthanized by $\mathrm{CO}_{2}$ narcosis and allowed to clot. Serum was separated by centrifugation and sterilized by filtration through 0.2 micron filters. Anti-LPS antibody titer was determined by ELISA as previously described [12]. Organs were processed and CFU-per-organ determined by serial dilution and plating as previously described [29].

2.4. Cytokine Production. In some experiments, production of IFN- $\gamma$ by antigen-stimulated spleen cells from immunized or sham-immunized mice was determined as previously described [12], except for the following: total spleen cells pooled from groups of 7 mice were incubated at $5 \times 10^{6} /$ well in 24 well tissue culture plates in $2 \mathrm{~mL}$ RPMI-1640 tissue culture medium supplemented with $10 \%$ fetal bovine serum, $2 \mathrm{mM}$ L-glutamine, $50 \mu \mathrm{M} 2$-mercaptoethanol, and $10 \mu \mathrm{g} / \mathrm{mL}$ gentamicin with or without $2 \mu \mathrm{g} / \mathrm{mL}$ concanavalin A (conA) or $2 \mu \mathrm{g} / \mathrm{mL}$ RFBL. After the entire mononuclear cell population was incubated together for $24 \mathrm{hrs}$ (in order to simulate the cytokine milieu that occurs in vivo), nonadherent cells were collected, pelleted at $1200 \mathrm{rpm}$ in a clinical centrifuge (Sorvall) for 7 minutes, and separated using the MACS separation system (Miltenyi Biotech) or resuspended in fresh medium and set aside on ice (unseparated cells). Separated CD8 and CD4+ T cells and unseparated cells were then replaced at the original concentration of mononuclear cells on the adherent spleen cells and incubation was continued for additional 48 hours in order to allow for cytokine production 
from individual $\mathrm{T}$ cell subtypes. The same cells that had been incubated with conA or RFBL were again incubated with these stimulants during this additional 48-hour period and unstimulated cells were again incubated with medium only. Culture supernatant fluids were then collected and sterilized by filtration through 0.2 micron filters. IFN- $\gamma$ concentration was determined by ELISA as previously described [12].

2.5. Flow Cytometry. The purity of CD4 and CD8+ T cell preparations was assessed by direct two-color immunofluorescence staining. Cells were frozen in $1 \%$ dimethyl sulfoxide in cell culture medium and stored at $-80^{\circ} \mathrm{C}$ until the day they were stained. Cells were warmed to $4^{\circ} \mathrm{C}$, concentrated by centrifugation, then resuspended in $4 \%$ methanol-free formaldehyde. Cells were incubated in formaldehyde for one hour to ensure sterility, then concentrated and washed with $0.1 \%$ bovine serum albumin in phosphate buffered saline (PBS/BSA). Cells were preincubated for $15 \mathrm{~min}$ at $4^{\circ} \mathrm{C}$ with purified rat anti-mouse CD16/CD32 (Mouse FC Block) (Pharmingen) to reduce nonspecific binding. Then cells were stained for $30 \mathrm{~min}$ at $4^{\circ} \mathrm{C}$ with CD4 FITC and CD8 PE antibodies and matched isotype IgG (Pharmingen). The staining was followed by washing with PBS/BSA in order to remove unbound antibody. Cells were resuspended in $\mathrm{PBS} / \mathrm{BSA}$ prior to acquisition on the flow cytometer. 10,000 events were acquired on a FACSort (Becton Dickinson Immunocytometry Systems, San Jose, CA, USA) and analyzed using CellQuest (Becton Dickinson) software. Data on the percentage of positive cells were obtained by setting a quadrant marker for nonspecific staining.

2.6. Statistical Methods. In the immunization and challenge studies, data from two separate but identical experiments were combined. The intensity of organ infection at 2 weeks after oral immunization, when most organs contained brucellae, was expressed as mean $+/-\mathrm{SD} \log _{10}$ CFU. Statistical significance of differences in means was determined by Student's $t$-test. When the raw CFU per organ was zero, the $\log$ transformed value was assigned a value of zero, but this value was used only for graphical representation, not for statistical comparison. At all time points after immunization when some animals had cleared infection from the harvested organs, the frequency of infection in each organ was determined and the significance of differences between groups was assessed using Fisher's exact test. Additionally, $\mathrm{CFU} /$ spleen at that time point was analyzed descriptively. IFN- $\gamma$ concentration was expressed as mean of triplicate or duplicate samples and analyzed descriptively.

\section{Results}

3.1. Clearance of WR201. In both repetitions of the experiment that we conducted to determine clearance of immunizing strain and subsequent protection against challenge infection, WR201 persisted for 8 weeks in spleens of 2 of 5 CD8 knockout mice but was cleared from all 5 normal (C57BL6/J control) animals at this time point. Intensity of infection was less than $100 \mathrm{CFU}$ in the infected spleens. Using combined data from these 2 experiments, this difference is significant ( $P=0.044$, Fisher's exact test). No other organs from either group were infected at this time point. In another pair of experiments, we immunized groups of 10 female perforin knockout, Fas mutant, CD8 knockout, and normal mice. In the first of these two experiments, all 10 mice of each group had completely cleared WR201 by eight weeks. In a repetition of the experiment, we examined the infection level at seven weeks and found that WR201 persisted at low levels in a minority of spleens of all groups. Infection levels in all mice that remained infected at this time point were less than $10 \mathrm{CFU} /$ organ. There was no statistically significant difference between the groups in terms of clearance or mean $\log$ CFU per spleen. These studies showed that, unlike male mice, female mice clear WR201 between 7 and 8 weeks after immunization and that perforin and Fas play no role in its clearance.

3.2. Immunization and Challenge of CD8 Knockout Mice. We performed two separate but identical experiments in which male CD8 knockout and normal C57BL/6 mice were immunized orally with WR201 or sham-immunized. Eight weeks later, all mice were challenged intranasally with virulent $16 \mathrm{M}$. We harvested spleens, lungs, and livers from mice 1 day and 2, 4 and 8 weeks following challenge to assess intensity and frequency of infection. At one day after challenge, all mice had Brucella in the lungs, but not in the liver or spleen (Figure 1). The course of infection in CD8 knockout and normal mice was indistinguishable (Figure 1). Immunized mice showed amelioration of spleen and liver infection, while immunization had no effect on clearance of virulent Brucella from the lung. In no case were culture results from C57BL/6 mice significantly different than results from CD8 knockout mice (immunized or naive) (Table 1).

Using combined data from the individual experiments, immunization with WR201 protected both C57BL/6 and CD8 knockout mice $(P<0.05)$ from infection in the liver and spleen at 2 and 4 weeks after challenge, but CD8 knockout mice were not protected in the spleen at 2 weeks. With the data from the 2 experiments combined, there was no significant difference in protection in any organ at any time point between mice of the same immunization status, that is, naive $\mathrm{C} 57 \mathrm{BL} / 6$ versus naive $\mathrm{CD} 8$ knockout mice or immunized C57BL/ 6 versus immunized CD8 knockout mice.

At eight weeks after challenge, using combined data from both experiments, spleens of both C57BL/6 and CD8 knockout mice were significantly protected (Table 1). There was no significant difference between mice of the same immunization status. While immunization led to significant protection of the liver of C57BL/6 mice $(P=0.011)$ but not CD8 knockout mice, the importance of this finding is uncertain, since most unimmunized animals of both strains had also cleared the infection from this organ by eight weeks.

As a further assessment of strain differences, we analyzed CFU per spleen at eight weeks after challenge for individual mice. In both immunized and nonimmunized groups, the highest splenic CFU among individual animals were found in CD8 knockout mice (not shown). Although this pattern 

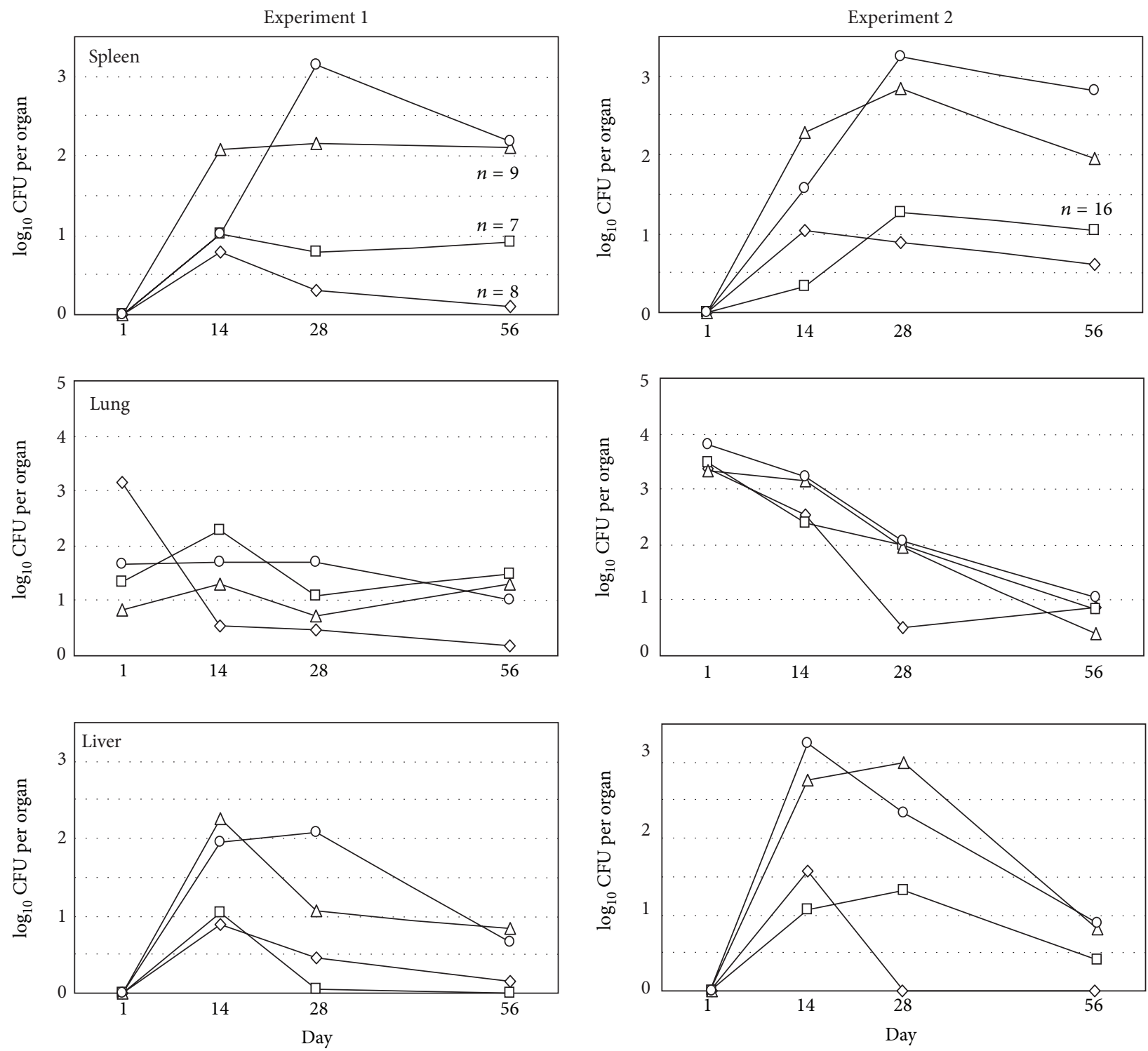

FIGURE 1: Immunization and challenge. Six-week-old male C57BL/6 and CD8 knockout mice were orally immunized with $10^{11}$ WR201 and eight weeks later challenged with $10^{4} \mathrm{~B}$. melitensis $16 \mathrm{M}$. Data points represent mean CFU per organ (limit of detection $=2$ ) for $4-5$ mice (first three time points) and 10 mice (56-day time point) except where noted. The figure shows naive CD8 knockout mice (circles), naive C57BL/6 mice (triangles), immune CD8 knockout mice (squares), and immune C57BL/6 mice (diamonds). In no case did mice of the same immunization status have significantly different CFU levels at a given time point in a given organ.

seemed suggestive of reduced anti-Brucella activity in knockout mice, analysis by Mann-Whitney $U$ test indicated that this trend was not significant.

\subsection{Cellular and Humoral Immune Responses in Immunized} Mice. To determine the ability of immune T cell subpopulations to respond to Brucella antigens, we collected spleen cells from female C57BL/6 mice immunized 8 weeks earlier with WR201. Cells were incubated with antigen or mitogen as described in methods. In both experiments, unseparated spleen cells and CD4 and CD8+ T cells from immunized mice produced more IFN- $\gamma$ than cells from unimmunized mice (data not shown). Cell separation was highly effective. By flow cytometric analysis, $\mathrm{T}$ cell subpopulations were at least $82 \%$ pure and were contaminated with less than $1 \%$ of the other T cell subset. Adherent cells alone and all cells that were incubated without RFBL failed to produce measurable IFN- $\gamma$ (not shown). All naive and immunized cells responded similarly to conA stimulation (not shown).

We measured anti-Brucella LPS IgG and IgG2a (shown, resp., in parentheses as mean calculated titer \pm SEM) in CD8 knockout $(7783 \pm 2284,62 \pm 28, n=10)$, perforin knockout $(4421 \pm 2072,41 \pm 20, n=10)$, Fas mutant $(5086 \pm 1388,67 \pm 16$, $n=7)$, and immunologically intact C57BL/6 (6893 \pm 1055 , 
TABLE 1: Six-week-old male C57BL/6 and CD8 knockout (CD8 KO) mice were orally immunized with $10^{11}$ WR201 and eight weeks later challenged with $10^{4} \mathrm{~B}$. melitensis $16 \mathrm{M}$. Figures at 1 day and 2 weeks after challenge, when most or all animals were infected, are mean CFU \pm SD. At 4 and 8 weeks, when many animals had cleared the infection and mean CFU counts became less meaningful, figures are shown as ratio of cleared/total. At day 1, $n=5$ for C57BL/ 6 and $n=4$ for CD8 KO; at 2 weeks $n=10$ for all groups. CFU comparisons utilized Student's $t$-test while clearance comparisons utilized Fisher's exact test.

\begin{tabular}{|c|c|c|c|c|c|c|c|c|c|}
\hline Organ & $\begin{array}{l}\text { Time after } \\
\text { challenge }\end{array}$ & $\begin{array}{c}\text { C57BL/6 } \\
\text { immunized }\end{array}$ & $\begin{array}{c}\text { C57BL/6 } \\
\text { naive }\end{array}$ & $\begin{array}{c}P \text { value } \\
\text { C57BL/6 } \\
\text { immunized } \\
\text { versus naive }\end{array}$ & $\begin{array}{c}\text { CD8 KO } \\
\text { immunized }\end{array}$ & $\begin{array}{l}\text { CD8 KO } \\
\text { naïve }\end{array}$ & $\begin{array}{c}P \text { value } \\
\text { CD8 KO } \\
\text { immunized } \\
\text { versus naive }\end{array}$ & $\begin{array}{c}P \text { value } \\
\text { immunized } \\
\text { versus } \\
\text { immunized } \\
\end{array}$ & $\begin{array}{l}P \text { value naïve } \\
\text { versus naive }\end{array}$ \\
\hline \multirow{3}{*}{ Liver } & 2 wks & $1.53 \pm 0.840$ & $2.91 \pm 0.646$ & $<0.01$ & $1.58 \pm 0.887$ & $2.88 \pm 0.646$ & $<0.05$ & $>0.05$ & $>0.05$ \\
\hline & 4 wks & $9 / 10$ & $1 / 10$ & $<0.001$ & $7 / 10$ & $0 / 10$ & $<0.01$ & $>0.05$ & $>0.05$ \\
\hline & 8 wks & $17 / 18$ & $11 / 19$ & $<0.05$ & $20 / 23$ & $14 / 20$ & $>0.05$ & $>0.05$ & $>0.05$ \\
\hline \multirow{3}{*}{ Spleen } & 2 wks & $1.29 \pm 0.676$ & $2.46 \pm 1.22$ & $<0.05$ & $1.59 \pm 0.227$ & $1.62 \pm 0.662$ & $>0.05$ & $>0.05$ & $>0.05$ \\
\hline & 4 wks & $6 / 10$ & $1 / 10$ & $<0.05$ & $6 / 10$ & $0 / 10$ & $<0.01$ & $>0.05$ & $>0.05$ \\
\hline & 8 wks & $12 / 18$ & $1 / 19$ & $<0.001$ & $12 / 23$ & $1 / 20$ & $<0.001$ & $>0.05$ & $>0.05$ \\
\hline \multirow{4}{*}{ Lung } & 1 day & $3.38 \pm 0.66$ & $3.32 \pm 0.18$ & $>0.05$ & $3.48 \pm 0.21$ & $3.81 \pm 0.14$ & $>0.05$ & $>0.05$ & $>0.05$ \\
\hline & 2 wks & $2.2 \pm 0.89$ & $2.03 \pm 1.17$ & $>0.05$ & $2.32 \pm 0.82$ & $3.08 \pm 0.66$ & $>0.05$ & $>0.05$ & 0.048 \\
\hline & 4 wks & $8 / 10$ & $4 / 10$ & $>0.05$ & $4 / 8$ & $1 / 10$ & $>0.05$ & $>0.05$ & $>0.05$ \\
\hline & 8 wks & $11 / 16$ & $11 / 19$ & $>0.05$ & $10 / 23$ & $10 / 20$ & $>0.05$ & $>0.05$ & $>0.05$ \\
\hline
\end{tabular}

$28 \pm 5.4, n=10)$ mice immunized 7 or 8 weeks previously with WR201. These studies did not show any significant differences in antibody levels among the groups.

\section{Discussion}

Because we found persistence of attenuated brucellae in the spleens of some male CD8 knockout mice at the time point at which others were subsequently challenged, it must be acknowledged that the apparent protection may be due in part to persistent macrophage activation. This exception may reflect a different pattern of dissemination to the spleens in CD8 knockout mice compared to the control animals. Subsequent experiments should entail a longer lag period prior to challenge in order to clarify this question. Nonetheless, in challenge experiments, naive CD8 knockout mice showed very similar kinetics of virulent brucellae dissemination and clearance as compared to normal C57BL/6 mice. It is important to note that day 1 data primarily indicates the fidelity of inoculation and has no relevance for assessment of protection.

The CD8+ $\mathrm{T}$ cell has been identified as an important mediator or component of the immune response to brucellosis caused by B. abortus in prior studies $[15,16,20-22,24$, $25,30,31]$. Since the species are closely related genetically, it seemed plausible that this cell type would play a similar role in the response to $B$. melitensis. If so, $\mathrm{CD} 8+\mathrm{T}$ cells would seem to be a useful target for vaccine development. CD8+ T cells may be preferentially stimulated by expressing costimulatory molecules and peptides with CD8+ T cell specific epitopes in nonprofessional phagocytes (i.e., cells not differentiated as macrophages) or by delivering antigens by viral vector [32]. Preferential stimulation of CD8+ T cells could be advantageous, because stimulation of $\mathrm{CD} 4+\mathrm{T}$ cells results in a mixed $\mathrm{T}$ helper 1 and $\mathrm{T}$ helper 2 response, that is, simultaneous production of IFN- $\gamma$ and IL-10 $[18,30]$.
The former response is important for anti-Brucella immunity, while the latter may play a counterregulatory or inhibitory role.

In preliminary studies [33], we were unable to detect cytotoxicity of immune CD8+ T cells for J774 macrophages infected with rough $B$. melitensis strain WRR51. The present studies were designed to determine whether CD8+ T cells play an essential role in vivo, by examining WR201-induced resistance to $B$. melitensis. Our results indicate that these cells are not crucial to protection in our model. In addition to the obvious difference (B. melitensis versus $B$. abortus), there are a number of other differences between the methods of our studies, which showed a minimal effect, and those used by others, who observed a strong effect $[15,16,30]$. First, there may be a fundamental difference in the immune response induced by immunization with the rough strain, RB51, and a smooth strain like WR201. Second, we used mice on a C57BL/6 background, while some other studies used animals on a $B A L B / c$ background. In some systems, the BALB/c mouse shows relative persistence of infection, which may indicate inherent differences in the immune response [18]. In limited studies from our group, C57BL/6 mice tended to be more resistant to intranasal challenge than $\mathrm{BALB} / \mathrm{c}$, although differences were not significant [29]. In addition, it is possible that one study that used MHC class I knockout mice as a surrogate for CD8-deficiency may have incorrectly attributed defective Brucella immunity to CD8+ T cells. Although these mice are CD8+ $\mathrm{T}$ cell deficient, they may have other defects (e.g., poor presentation of CD1-binding antigens) that may explain their impaired ability to control infection [34]. Third, our routes of immunization and challenge are different; we immunized orally and challenged intranasally, while other groups immunized and challenged i.v. $[15,30]$. It is possible that challenge by a nonmucosal route, as in these previous studies, overestimates the impact of CD8+ cells. The relative importance of variables such as these could be assessed in 
additional studies. Our results do not exclude a role for CD8+ T cells in naturally acquired brucellosis or in other experimental systems but indicate that they are not critical for WR201-mediated protection against intranasal B. melitensis challenge.

There are, however, some suggestions in these studies that CD8+ T cells may contribute to anti-Brucella effects in our model. In the studies in male mice, infection with WR201 was slightly, but significantly, more prolonged in CD8 knockout compared to normal animals. Similarly, there were trends toward higher intensity of infection and higher frequency of infection in spleens of both immunized and nonimmunized 16M-challenged CD8 knockout mice compared to corresponding normal mice. These differences are minor, however, and suggest a contribution of CD8+ T cells rather than a predominant effect. The near-identical infection of other organs between knockout and normal mice, however, supports the view that this contribution is of limited importance. The studies using perforin and Fas knockout mice also did not support a role for CD8 $+\mathrm{T}$ cell cytotoxicity as an important determinant of immunity to Brucella, in agreement with studies done on a B. abortus model [17, 35]. It is notable that we did not see differences between knockout and normal mice in our studies using female mice. While this variability may reflect inherent differences in immune responsiveness between the sexes, it may also reflect different levels of stress in these groups. Stress is experienced far more by group-housed male mice, to varying degrees by individual mice within a given group, and plays a critical role in their immune response [36]. It has been hypothesized that a key role for the CD8+ $\mathrm{T}$ cell is the suppression of production of $\mathrm{T}$ helper 2 type cytokines [30]. It may be that environmental factors, for example, stress in male mice, influence the overall trend of the $\mathrm{T}$ helper response and that, in certain circumstances, the $\mathrm{CD} 8+\mathrm{T}$ cell plays a compensatory role.

It is possible that the role for the $\mathrm{CD} 8+\mathrm{T}$ cell in murine infection with $B$. abortus is not applicable to infection with $B$. melitensis as in the present study $[15,16,30,31]$. Perhaps the immune response to $B$. abortus relies more heavily on the CD8+ T cell. This may stem from the unusual property of B. abortus LPS to cross link MHC-II molecules, which could inhibit the CD4+ T cell response [37]. IFN- $\gamma$ is essential for survival in the face of virulent Brucella in vivo [17] and mediates reduction in intracellular infection of cultured macrophages $[38,39]$. Previous studies with CD4+ T cells, however, have shown that the CD4+ T cell is the major producer of IFN- $\gamma$ in brucellosis $[16,18,19]$. We confirm these studies in B. melitensis-immunized mice and extend them by demonstrating that both $\mathrm{CD} 4+$ and $\mathrm{CD} 8+\mathrm{T}$ cells produced IFN- $\gamma$ in response to specific antigen, suggesting that both cell types should contribute to protective responses. These studies raise new questions about the importance of CD8+ $\mathrm{T}$ cells in defense against Brucella and suggest that the issue should be reexamined for $B$. abortus. They also suggest that a vaccine strategy aimed at sensitizing CD8+ T cells may have limited value, although this question also deserves further investigation.

\section{Disclosure}

The opinions or assertions contained herein are the private views of the authors and are not to be construed as official or as reflecting the views of the Departments of the Army, Navy, Air Force, or the Department of Defense. Research was conducted in compliance with the Animal Welfare Act and other federal statutes and regulations relating to animals and experiments involving animals and adheres to principles stated in the Guide for the Care and Use of Laboratory Animals, NRC Publication, 1996 edition.

\section{Acknowledgments}

This work was supported by funding from the Department of Defense Military Infectious Diseases Research Program. The authors honor the memory of the late Dr. Ela Zelazowska whose work was an invaluable contribution to this effort.

\section{References}

[1] M. L. Boschiroli, V. Foulongne, and D. O’Callaghan, "Brucellosis: a worldwide zoonosis," Current Opinion in Microbiology, vol. 4, no. 1, pp. 58-64, 2001.

[2] J. Godfroid and A. Käsbohrer, "Brucellosis in the European Union and Norway at the turn of the twenty-first century," Veterinary Microbiology, vol. 90, no. 1-4, pp. 135-145, 2002.

[3] E. Moreno, "Brucellosis in Central America," Veterinary Microbiology, vol. 90, no. 1-4, pp. 31-38, 2002.

[4] M. Refai, "Incidence and control of brucellosis in the Near East region," Veterinary Microbiology, vol. 90, no. 1-4, pp. 81-110, 2002.

[5] M. Banai, "Control of small ruminant brucellosis by use of Brucella melitensis Rev.1 vaccine: laboratory aspects and field observations," Veterinary Microbiology, vol. 90, no. 1-4, pp. 497519,2002

[6] B. Robinson-Dunn, “The microbiology laboratory's role in response to bioterrorism," Archives of Pathology and Laboratory Medicine, vol. 126, no. 3, pp. 291-294, 2002.

[7] J. A. Montaraz and A. J. Winter, "Comparison of living and nonliving vaccines for Brucella abortus in BALB/c mice," Infection and Immunity, vol. 53, no. 2, pp. 245-251, 1986.

[8] Y. Zhan, A. Kelso, and C. Cheers, "Differential activation of Brucella-reactive $\mathrm{CD} 4^{+} \mathrm{T}$ cells by Brucella infection or immunization with antigenic extracts," Infection and Immunity, vol. 63, no. 3, pp. 969-975, 1995.

[9] M. J. Corbel, "Brucellosis: an overview," Emerging Infectious Diseases, vol. 3, no. 2, pp. 213-221, 1997.

[10] F. M. M. Aldomy, K. L. Jahans, and Y. H. Altarazi, "Isolation of Brucella melitensis from aborting ruminants in Jordan," Journal of Comparative Pathology, vol. 107, no. 2, pp. 239-242, 1992.

[11] N. F. Cheville, "Development, testing and commercialization of a new brucellosis vaccine for cattle," Annals of the New York Academy of Sciences, vol. 916, pp. 147-153, 2000.

[12] D. L. Hoover, R. M. Crawford, L. L. van de Verg et al., "Protection of mice against brucellosis by vaccination with Brucella melitensis WR201 (16M $\triangle$ purEK)," Infection and Immunity, vol. 67, no. 11, pp. 5877-5884, 1999.

[13] C. Cheers and M. Ho, "Resistance and susceptibility of mice to bacterial infection. IV. Functional specificity in natural 
resistance to facultative intracellular bacteria," RES Journal of the Reticuloendothelial Society, vol. 34, no. 4, pp. 299-309, 1983.

[14] M. Plommet and A. M. Plommet, "Immune serum-mediated effects on brucellosis evolution in mice," Infection and Immunity, vol. 41, no. 1, pp. 97-105, 1983.

[15] L. N. Araya, P. H. Elzer, G. E. Rowe, F. M. Enright, and A. J. Winter, "Temporal development of protective cell-mediated and humoral immunity in BALB/c mice infected with Brucella abortus," Journal of Immunology, vol. 143, no. 10, pp. 3330-3337, 1989.

[16] Y. He, R. Vemulapalli, A. Zeytun, and G. G. Schurig, "Induction of specific cytotoxic lymphocytes in mice vaccinated with Brucella abortus RB51," Infection and Immunity, vol. 69, no. 9, pp. 5502-5508, 2001.

[17] E. A. Murphy, J. Sathiyaseelan, M. A. Parent, B. Zou, and C. L. Baldwin, "Interferon- $\gamma$ is crucial for surviving a Brucella abortus infection in both resistant $\mathrm{C} 57 \mathrm{BL} / 6$ and susceptible BALB/c mice," Immunology, vol. 103, no. 4, pp. 511-518, 2001.

[18] D. M. Fernandes, X. Jiang, J. H. Jung, and C. L. Baldwin, "Comparison of $\mathrm{T}$ cell cytokines in resistant and susceptible mice infected with virulent Brucella abortus strain 2308," FEMS Immunology and Medical Microbiology, vol. 16, no. 3-4, pp. 193203, 1996.

[19] Y. Zhan, J. Yang, and C. Cheers, "Cytokine response of T-cell subsets from Brucella abortus-infected mice to soluble Brucella proteins," Infection and Immunity, vol. 61, no. 7, pp. 2841-2847, 1993.

[20] K. A. Pasquevich, S. M. Estein, C. G. Samartino et al., "Immunization with recombinant Brucella species outer membrane protein Omp16 or Omp19 in adjuvant induces specific $\mathrm{CD}^{+}$ and $\mathrm{CD}^{+} \mathrm{T}$ cells as well as systemic and oral protection against Brucella abortus infection," Infection and Immunity, vol. 77, no. 1, pp. 436-445, 2009.

[21] D. Goel, V. Rajendran, P. C. Ghosh, and R. Bhatnagar, "Cell mediated immune response after challenge in Omp25 liposome immunized mice contributes to protection against virulent Brucella abortus 544," Vaccine, vol. 31, no. 8, pp. 1231-1237, 2013.

[22] X. D. Hu, S. T. Chen, J. Y. Li, D. H. Yu, H. Cai, and Y. Yi-Zhang, "An IL-15 adjuvant enhances the efficacy of a combined DNA vaccine against Brucella by increasing the $\mathrm{CD} 8^{+}$cytotoxic $\mathrm{T}$ cell response," Vaccine, vol. 28, no. 12, pp. 2408-2415, 2010.

[23] A. P. M. S. Brandão, F. S. Oliveira, N. B. Carvalho et al., "Host susceptibility to Brucella abortus infection is more pronounced in IFN- $\gamma$ knockout than IL-12/ $\beta 2$-microglobulin double-deficient mice," Clinical and Developmental Immunology, vol. 2012, Article ID 589494, 7 pages, 2012.

[24] P. Barrionuevo, M. V. Delpino, R. G. Pozner, L. N. Velásquez, J. Cassataro, and G. H. Giambartolomei, "Brucella abortus induces intracellular retention of MHC-I molecules in human macrophages down-modulating cytotoxic $\mathrm{CD}^{+} \mathrm{T}$ cell responses," Cellular Microbiology, vol. 15, no. 4, pp. 487-502, 2013.

[25] M. Durward, G. Radhakrishnan, J. Harms, C. Bareiss, D. Magnani, and G. A. Splitter, "Active evasion of CTL mediated killing and low quality responding $\mathrm{CD}^{+} \mathrm{T}$ cells contribute to persistence of brucellosis," PLoS ONE, vol. 7, no. 4, Article ID e34925, 2012.

[26] M. A. Durward, J. Harms, D. M. Magnani, L. Eskra, and G. A. Splitter, "Discordant Brucella melitensis antigens yield cognate CD8 T cells in vivo," Infection and Immunity, vol. 78, no. 1, pp. 168-176, 2010.
[27] M. A. Vitry, C. De Trez, S. Goriely et al., "Crucial role of $\gamma$ interferon-producing $\mathrm{CD} 4^{+} \mathrm{Th} 1$ cells but dispensable function of CD8 ${ }^{+} \mathrm{T}$ cell, B cell, Th2, and Th17 responses in the control of Brucella melitensis infection in mice," Infection and Immunity, vol. 80, no. 12, pp. 4271-4280, 2012.

[28] M. J. Izadjoo, A. K. Bhattacharjee, C. M. Paranavitana, T. L. Hadfield, and D. L. Hoover, "Oral vaccination with Brucella melitensis WR201 protects mice against intranasal challenge with virulent Brucella melitensis 16M," Infection and Immunity, vol. 72, no. 7, pp. 4031-4039, 2004.

[29] M. J. Izadjoo, Y. Polotsky, M. G. Mense et al., "Impaired control of Brucella melitensis infection in Rag1-deficient mice," Infection and Immunity, vol. 68, no. 9, pp. 5314-5320, 2000.

[30] S. C. Oliveira and G. A. Splitter, "CD8 $8^{+}$type $1 \mathrm{CD} 44^{h i} \mathrm{CD} 45 \mathrm{RB}^{l o}$ $\mathrm{T}$ lymphocytes control intracellular Brucella abortus infection as demonstrated in major histocompatibility complex class Iand class II-deficient mice," European Journal of Immunology, vol. 25, no. 9, pp. 2551-2557, 1995.

[31] H. Pavlov, M. Hogarth, F. C. McKenzie, and C. Cheers, "In vivo and in vitro effects of monoclonal antibody to Ly antigens on immunity to infection," Cellular Immunology, vol. 71, no. 1, pp. 127-138, 1982.

[32] S. E. Townsend and J. P. Allison, “Tumor rejection after direct costimulation of $\mathrm{CD}^{+} \mathrm{T}$ cells by B7-transfected melanoma cells," Science, vol. 259, no. 5093, pp. 368-370, 1993.

[33] S. L. Yingst, The role of the $C D 8^{+} T$ cell in the immune response to Brucella melitensis in mice [Ph.D. thesis], Department of Basic Medical Sciences, Purdue University School of Veterinary Medicine, 2003.

[34] M. J. Soloski, M. E. Szperka, A. Davies, and S. L. Wooden, "Host immune response to intracellular bacteria: a role for MHClinked class-Ib antigen-presenting molecules," Experimental Biology and Medicine, vol. 224, no. 4, pp. 231-239, 2000.

[35] E. A. Murphy, M. Parent, J. Sathiyaseelan, X. Jiang, and C. L. Baldwin, "Immune control of Brucella abortus 2308 infections in BALB/c mice," FEMS Immunology and Medical Microbiology, vol. 32, no. 1, pp. 85-88, 2001.

[36] K. M. Wonnacott and R. H. Bonneau, "The effects of stress on memory cytotoxic $\mathrm{T}$ lymphocyte-mediated protection against herpes simplex virus infection at mucosal sites," Brain, Behavior, and Immunity, vol. 16, no. 2, pp. 104-117, 2002.

[37] C. Forestier, F. Deleuil, N. Lapaque, E. Moreno, and J. P. Gorvel, "Brucella abortus lipopolysaccharide in murine peritoneal macrophages acts as a down-regulator of T cell activation," Journal of Immunology, vol. 165, no. 9, pp. 5202-5210, 2000.

[38] M. O. Eze, L. Yuan, R. M. Crawford et al., "Effects of opsonization and $\gamma$ interferon on growth of Brucella melitensis $16 \mathrm{M}$ in mouse peritoneal macrophages in vitro," Infection and Immunity, vol. 68, no. 1, pp. 257-263, 2000.

[39] X. Jiang and C. L. Baldwin, "Effects of cytokines on intracellular growth of Brucella abortus," Infection and Immunity, vol. 61, no. 1, pp. 124-134, 1993. 


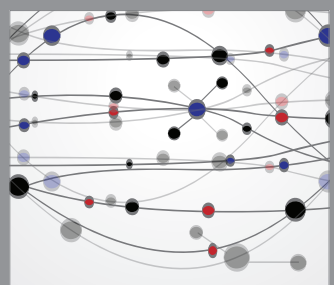

The Scientific World Journal
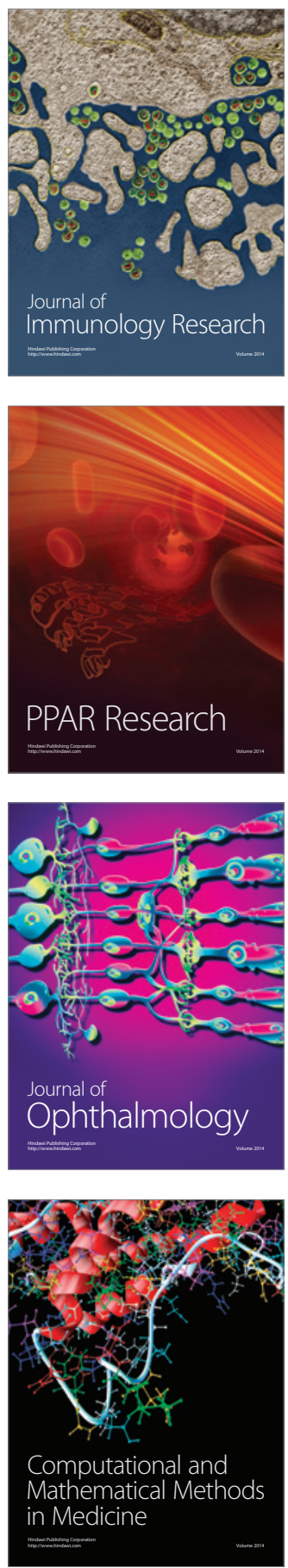

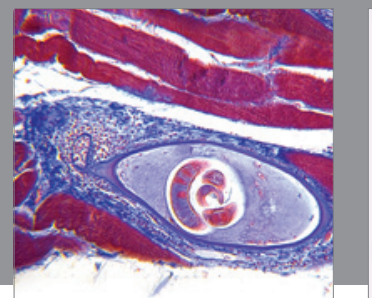

Gastroenterology

Research and Practice
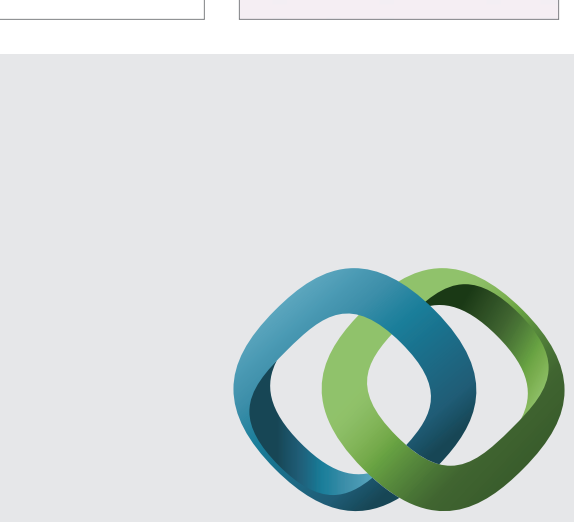

\section{Hindawi}

Submit your manuscripts at

http://www.hindawi.com
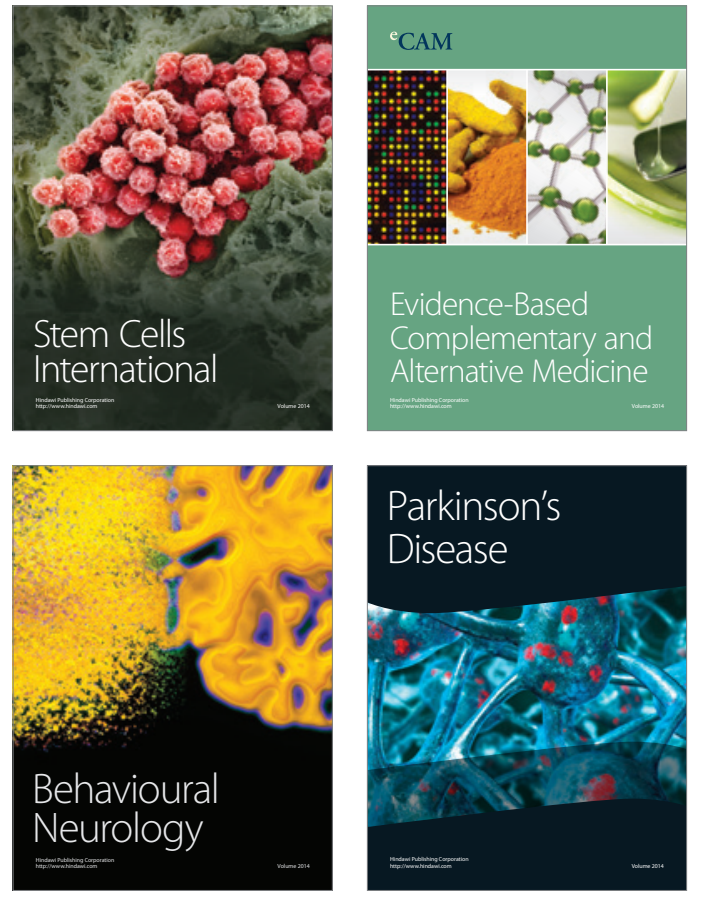
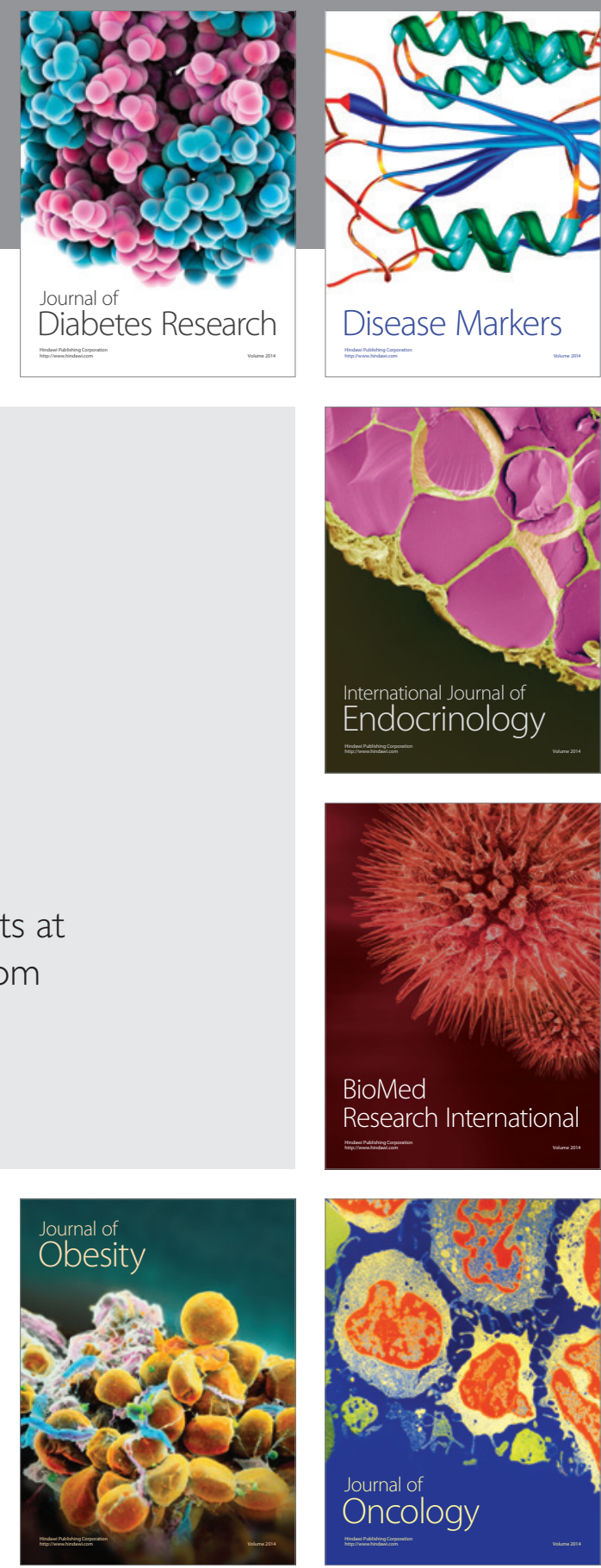

Disease Markers
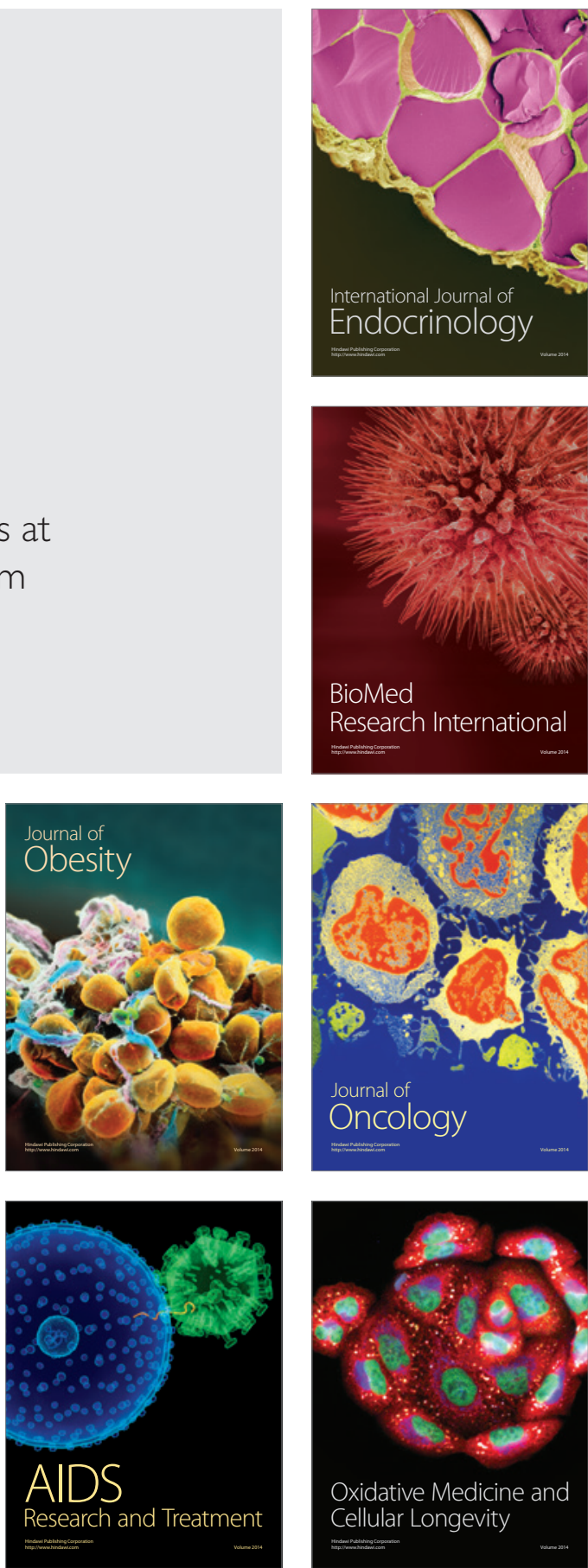